$M^{a}$ Gracia Gómez de Terreros Guardiola

Figura 1. Fachada sur con la portada centrada en la misma y atribuida a Vandelvira. Fotografia: $\mathrm{M}^{\mathrm{a}}$ Gracia Gómez de Terreros G.

Doctora Arquitecta Profesora Titular de Universidad

Departamento Construcciones Arquitectónicas 2

Universidad de Sevilla

\title{
La dialéctica entre lo original y lo nuevo \\ La restauración de la iglesia del cuartel de San Hermenegildo de Sevilla
}

Keywords: Restorative intervention, environment, image, authorship, design, authenticity

The church of the old school of Saint Hermegildo in Seville is a paradigm of our heritage in its authenticity. The temple is the last vestige of the old school, at that time barracks, which was demolished in 1957-58, leaving it exempt and in need of the restitution of an adequate image, compulsory from a patrimonial and urban perspective. Félix Hernández Giménez carried out its restoration in 1960-67, designing new shapes and elements for the building such as the front of the south facade, which was wrongly attributed to Alonso de Vandelvi$r a$, as is proved in this article. The analysis of nine located projects of Hernandez and the auxiliary architect Rafael Manzano Martos and the information obtained from other sources verify this intervention without subtracting value from the building. Its formal modifications, the proper location of the building in its emplacement, as well as all the historical events that happened there are part of the building and its authenticity. ${ }^{1}$

\section{El edificio y la iglesia. Vicisitudes}

El antiguo colegio de San Hermenegildo, fundado por la Compañia de Jesús en 1580, inició su construcción en 1587 (Marín Fidalgo 2008: 308). La traza de la iglesia se encargó en 1616 al hermano arquitecto Pedro Sánchez, quien entre 1616-19 llevó a cabo su ejecución (Rodríguez G. de Ceballos 1997: 125-138, Criado Mainar 2010: 264-265). La iglesia presenta una tipología arquitectónica poco usual entre los jesuitas, tiene una planta eliptica inscrita en un rectángulo y se cubre con una cúpula ovalada. Su intradós está adornado con ricas yeserías constituyendo una obra manierista con decoración de un barroco incipiente, ejecutada en 1619-29 por Francisco de Herrera el Viejo (Pérez Sánchez y Navarrete Prieto 1996: 365-387). Cuenta como antecedente y modelo con la Sala Capitular de la catedral de Sevilla, obra de Hernán Ruiz II, de 1568 (Morales et al. 2004: 224-225) Además, como aspecto a rebatir, la base de datos del Instituto Andaluz del Patrimonio Histórico (IAPH) apunta que "La portada parece ser obra de Alonso de Vandelvira" (figura 1).

El colegio sufrió vicisitudes con el paso de los años (Marin Fidalgo 2008: 322-323). Tras la expulsión de los jesuitas, siguió funcionando como colegio; en 1776, fue hospicio de los niños Toribios; en 1802, pasó a cuartel militar; durante la invasión francesa el templo sufrió daños y saqueos; en 1832, se celebraron en la iglesia las sesiones de las primeras Cortes Constitucionales; y, finalmente, se transformó en cuartel, sede del Regimiento de

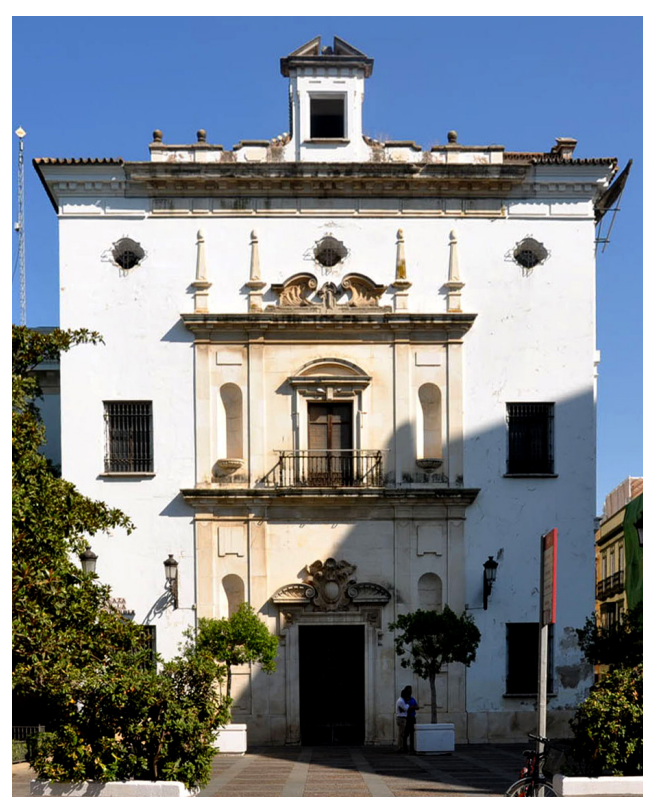

Infantería 9, lugar donde el sábado 18 de julio de 1936 se inició el Alzamiento Nacional en la ciudad (ABC 1961a: 18). ${ }^{2}$ El edificio siguió como cuartel hasta 1956, cuando lo compró el Ayuntamiento y seguidamente fue derribado, salvándose únicamente su iglesia, que ha pasado por diversos destinos: oficina técnica de la Comisaría de Monumentos, Museo de Arte Contemporáneo, oficina municipal, sede provisional del Salón de Plenos del Parlamento Andaluz (1985-1992), cobijó en 2003 las imágenes de la Hermandad de Jesús de la Pasión. Actualmente es sede de actos culturales del Ayuntamiento, aunque está clausurada desde 2006 por motivos de seguridad. 


\section{El nuevo espacio urbano y la salvación de la iglesia}

El derribo del cuartel fue una actuación urbanística llevada a cabo en este sector por el Ayuntamiento de Sevilla, y que era parte de un largo proceso de intervención sobre el singular trazado de una ciudad con esencia islámica y de gran complejidad a la hora de acometer su planeamiento urbano. Ya en el siglo XIX se iniciaron en la ciudad actuaciones con fines higienistas (Suarez Garmendia 1986: 14, 25-28, 89-90 y 227-231), con cierto paralelismo con Madrid, que perseguian sanear, modernizar su núcleo urbano y mejorar las comunicaciones en la ciudad. Se derribaron gran parte de la muralla y edificios, normalmente religiosos, que generaron ensanches de espacios y plazas como la plaza Nueva, de la Encarnación, de la Magdalena, de la Gavidia, etc., y se trataron de propiciar alineaciones y ensanches de vías públicas en un urbanismo laberintico con ausencia de calles rectas. Las principales circulaciones de la ciudad marcaban históricamente las direcciones norte-sur y este-oeste, y ya se señalaron como dos grandes ejes en el proyecto de reforma interior del casco urbano, redactado por José Sáez y López en 1895. El eje norte-sur se consiguió generar en los años 20 del siglo XX (Villar Movellán 1979: 97, 107-109), en parte gracias a la Exposición Iberoamericana de 1929, y permitió organizar la Avenida de la Constitución (Tejido Jiménez 2016: 3-11), aunque conllevó los derribos del colegio dominico de Santo Tomás y del Santa María de Jesús (Gómez de Terreros 2009: 90-91).

En las dos décadas siguientes a la Guerra Civil el Ayuntamiento continuaba en la bancarrota generada por la exposición del 29 y tenia, además, otros problemas acuciantes que resolver, como la escasez de viviendas provocada por los trasvases de población del medio rural al urbano y el abastecimiento de aguas a la ciudad. Asi pues, aunque se proyectaron varios planes parciales de mejora del casco urbano para facilitar la circulación este-oeste, que fueron recogidos incluso en el primer Plan General de Ordenación Urbana de Sevilla de 1946, no fue hasta el Plan de reformas viarias de 1957 (y su posterior ampliación en 1958) cuando se comenzaron a llevar a cabo. Uno de estos planes planteaba generar una plaza-espacio entre la plaza de la Gavidia y la plaza del Duque mediante el derribo del cuartel de San Hermenegildo (Fernández Salinas 1998: 97-119 y 206-210) (figuras 2 y 3), constituyendo, como bien señala Ayús y Rubio (2017: 67-70), un claro ejemplo de cómo

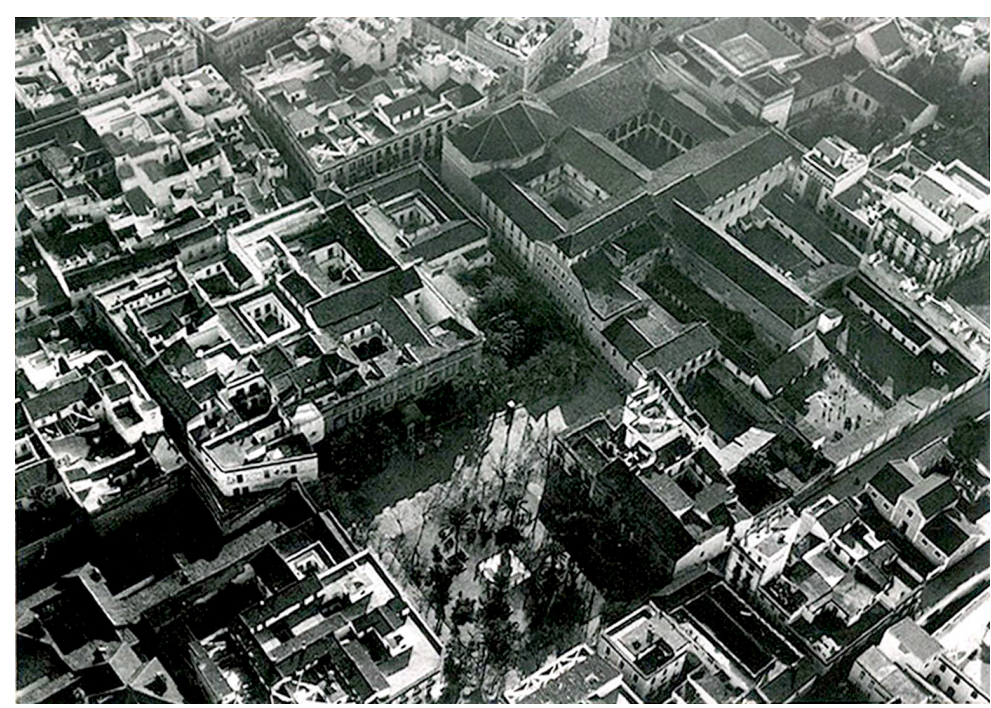

la administración ha constituido uno de los principales artífices de la destrucción de las arquitecturas y paisajes de nuestras ciudades.

El Inventario de la Secretaria General del Ayuntamiento de Sevilla (ISGAS 1956) contiene una copia de la escritura de compra del cuartel por el Ayuntamiento que la fecha el 22 de diciembre de 1956. Y, para regularizar el espacio, seguidamente se iniciaron expedientes de expropiaron de algunas casas del entorno. Inicialmente se planteó conservar la iglesia, aunque el Ayuntamiento no mantenía una postura clara En el verano de 1957 comenzó el derribo del cuartel (ABC 1957:21), momento en el que la Comisión Provincial de Monumentos, como consta en sus Actas, (ACMHAPS 1957: 333) solicitó información respecto a la iglesia, a lo que se respondió:

Figura 2. Vista parcial de la ciudad. Plaza de la Gavidia y edificio de Capitanía General. Cuartel del Duque y cuartel de la Gavidia con la iglesia de San Hermenegildo anexa. 1926. Fuente: CICAS-SAHP. Fototeca Municipal de Sevilla, fondo Serrano.

Figura 3. Fachada este del cuartel y de la iglesia anexa antes de terminar la demolición. Fotografia: Antonio Palau (detalle). Colegio San Hermenegildo. 20-8-1957. Fuente: SGI Fototeca-Laboratorio de Arte Universidad de Sevilla.

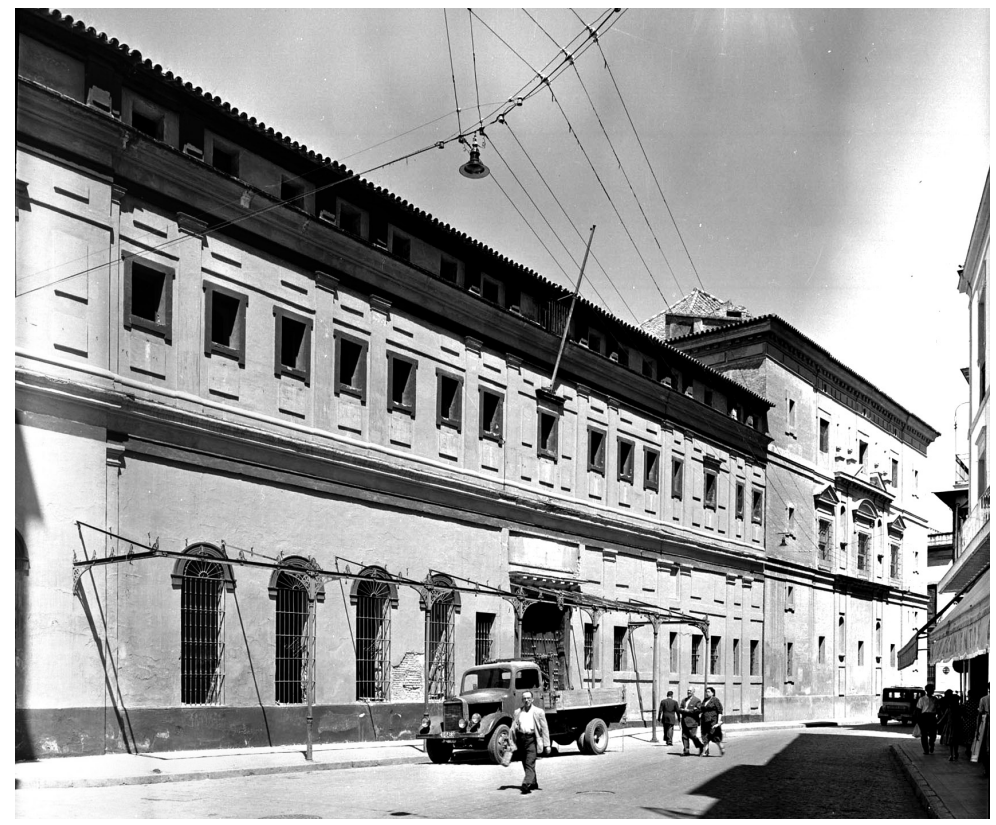




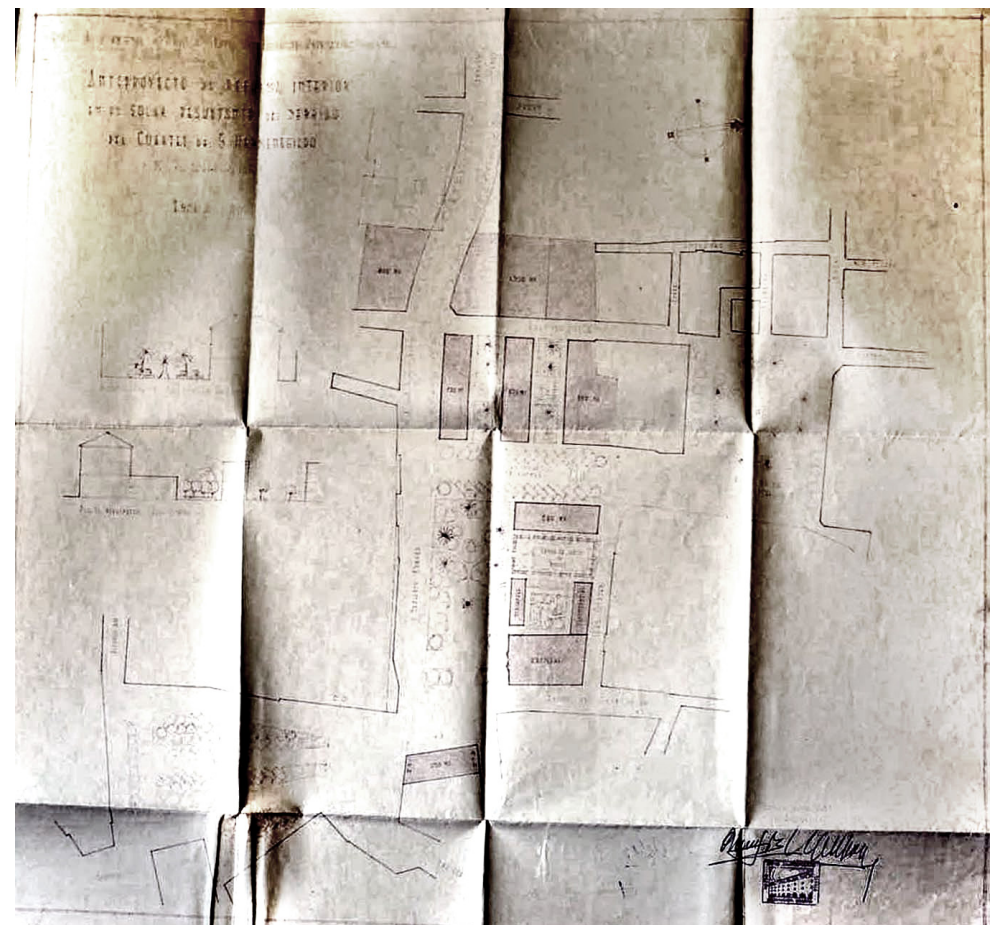

Figura 4. Plano del Anteproyecto de reforma interior del solar resultante del derribo del cuartel y del picadero militar, OTOUAS 1957. Fuente: ACMHAPS, Caja Planos y proyectos de Edificios Sevilla, 18.

Figura 5. Aspecto del solar tras el derribo total del cuartel, ca. 1960. Fotografía de Serrano y publicada por Nicolás Salas en Sevilla desaparecida. Álbum de la destrucción de la ciudad (Siglos XIX y XX).

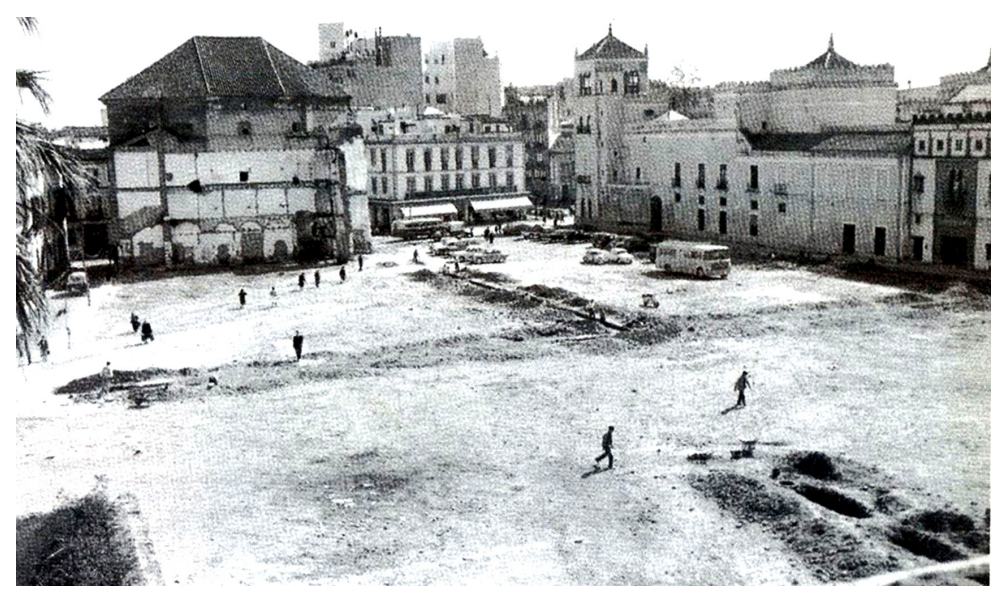

iglesia y el Ayuntamiento consideró su derribo, lo que motivó que la Comisión de Monumentos solicitase su declaración de monumento, a la vez que planteaba que el edificio volviese a su función original (Hernández Diaz 1958: 23-24). ${ }^{3}$ Entre 1958 y 1959 se redactaron varios proyectos de reforma interior y de pavimentación y arbolado del solar, que respetaban la iglesia, llevándose a cabo estas obras en 1960-61 (Fernández Salinas 1998: 211-215, Archivo Municipal de Sevilla (AMS) 1959-1961, ABC 1961b:29). ${ }^{4}$ Una fotografia de estos años muestra el solar tras el derribo del cuartel y el aspecto desolador que presentaba la iglesia hacia este nuevo espacio (figura 5), al mostrar, por sus lados el oeste y sur, restos de muros y tabiques del edificio demolido.

En 1963 se edificó en el suroeste del solar el edificio de la Jefatura Superior de Policía, de moderna traza, que dejó el espacio ordenado y pendiente de la restauración de la iglesia. Es interesante plantear como, a pesar de la desaparición del cuartel, el nuevo espacio generado no se liberó de su pasado, ni de su imagen y simbología asociadas, al imponérsele en 1960 el nombre de Plaza del 18 de Julio, manteniendo como apunta González-Varas Ibáñez (2016b: 561-564) una obsesión memorialista que muchas veces acompaña al elemento patrimonial, y que, en cierta medida se mantuvo tras la vuelta al régimen democrático cuando, en 1980, se cambió su nombre por Plaza de la Concordia.

El derribo del cuartel había constituido una actuación violenta que dejó exenta la iglesia recién declarada monumento, que ofrecía una imagen ruinosa, mutilada y descompuesta, transformada en un residuo grosero; perdida su potencialidad y degradando entorno urbano. Era imperiosa una intervención que le devolviese la dignidad y valor histórico al edificio y una adecuada presentación a su entorno, tal y como ya requería la opinión pública. $\mathrm{Y}$, en septiembre de 1959, a pesar que consideraba que no le correspondia, el alcalde encargó a la Oficina Técnica Municipal de Ordenación Urbana la redacción de un proyecto de restauración de la iglesia (Gómez Estern 1959) que fue enviado al Ministerio de Educación Nacional, junto con un escrito en el que indicaba: "...pero sin estar definidas las obras”, y se rogaba:

...la realización por el Estado de las obras necesarias, a fin de dejar el edificio de referencia en las condiciones que reclama la clasificación nacional que hoy tiene, máxime teniendo en cuenta, además del pésimo estado en que 
el mismo se encuentra, el lugar de su emplazamiento.

En diciembre de 1959, la Dirección General de BBAA remitió esta documentación al arquitecto de la $6^{a}$ Zona del Servicio de Defensa del Patrimonio Artístico Nacional, Félix Hernández Giménez, con un escrito en el que se le instaba a que "se informe lo que estime pertinente sobre el particular". ${ }^{5}$

El proyecto era en realidad un presupuesto que evaluaba las obras en 2.000.856 pts. Algunas de sus partidas son reveladoras, como las referidas a la demolición, recalce y reconstrucción del muro de la fachada sur "reproduciendo arcos y huecos de entrada y superiores en su forma actual"; o las restauraciones de las fachadas sur y este, indicando para la primera "con formación de portada", dando a entender la inexistencia de la misma. Así pues, se planteaba, sin entrar ni plantear cuestiones que generasen polémicas restauradoras, el generar un falso histórico, al tratar sencillamente de reproducir algunos elementos en su forma original, sin distintivos.

\section{La restauración de la iglesia. Proyectos y obras}

De esta manera, Félix Hernández se encontró con un monumento nacional, exento, en aparente mal estado, desvinculado de su entorno y origen y que requería una urgente intervención que le restituyese una adecuada imagen para la ciudad. No había posibilidad alguna de "reconstrucción" de algo que nunca habia existido, lo que justificaba una restauración que incluía el aporte de elementos que completasen, volvieran a poner en valor y permitiesen dar nuevamente uso al edificio (Stanley-Price 2009: 35-47).

Las restauraciones de Hernández se han considerado conservadoras y asociadas a la mera consolidación monumental (Muñoz Cosme 1989: 132,151), si bien esta imagen puede deberse a que muchos de los monumentos de la $6^{\mathrm{a}}$ Zona presentaban un lamentable estado debido a la falta de actuaciones de simple mantenimiento y a que requerían este tipo de intervención. ${ }^{6}$ Una particularidad del arquitecto era la parquedad de sus proyectos, con escuetas memorias que apuntaban las obras que pretendia realizar y que se ejecutaban según la subvención concedida; $y$ un único plano de planta general, al que se añadian más si eran requeridos elementos de nueva factura.

La intervención en la Iglesia de San Her- menegildo se efectuó, como era habitual en esos años, mediante la redacción y ejecución sucesivos proyectos; 9 en este caso (7 de Hernández, 1 de Rafael Manzano y 1 de ambos), fechados entre 1960 y 1967, que actualmente se custodian en el fondo de Cultura del Archivo General de la Administración (AGA), de Alcalá de Henares. El análisis de los proyectos revela que la restauración del monumento tuvo que resolver temas formales, técnicos y funcionales y, además, urbanísticos; y permite apreciar algunas de las soluciones dadas y plantear el desarrollo de las obras, aunque su parquedad ha requerido la búsqueda de información en otras fuentes que corroboren la autoría de la portada sur.

Los dos primeros proyectos de Hernández (1960 y 1961) fueron una toma de contacto con el monumento y su realidad. Y tal y como era previsible, las obras se iniciaron por el exterior. Sus memorias plantearon recalces, consolidaciones y resanados de muros, pilares y arquerias, y la reposición y refuerzo del tejado. El segundo mostraba mayor conocimiento del edificio por parte del arquitecto, al sumar a estas obras, las de la limpieza y consolidación de elementos del interior. No describian el estado de la iglesia ni hacian referencia alguna a sus necesidades. Ambos proyectos contenían un solo plano de la planta, unas mediciones con 7 partidas y un escaso presupuesto, de 160.000 y 200.000 pts., respectivamente. Una fotografia de 1960, previa a la intervención de Hernández, muestra la inexistencia de portada alguna en esta fachada sur; solo existía la puerta de acceso a la iglesia en planta baja (figura 6). Esto desdice la autoría de la misma por Alonso de Vandelvira, quien probablemente realizó la del colegio, que desapareció en las obras de adaptación a cuartel (Cruz Isidoro 2001: 103-
Figura 6. Lateral sur de la iglesia tras el derribo del cuartel. Muestra la inexistencia de portada en ella, la plaza ya urbanizada. Fuente: (C) ICAS-SAHP. Fototeca Municipal de Sevilla. Fondo Cubiles Capilla de San Hermenegildo en obras. Exterior. 09-1960.

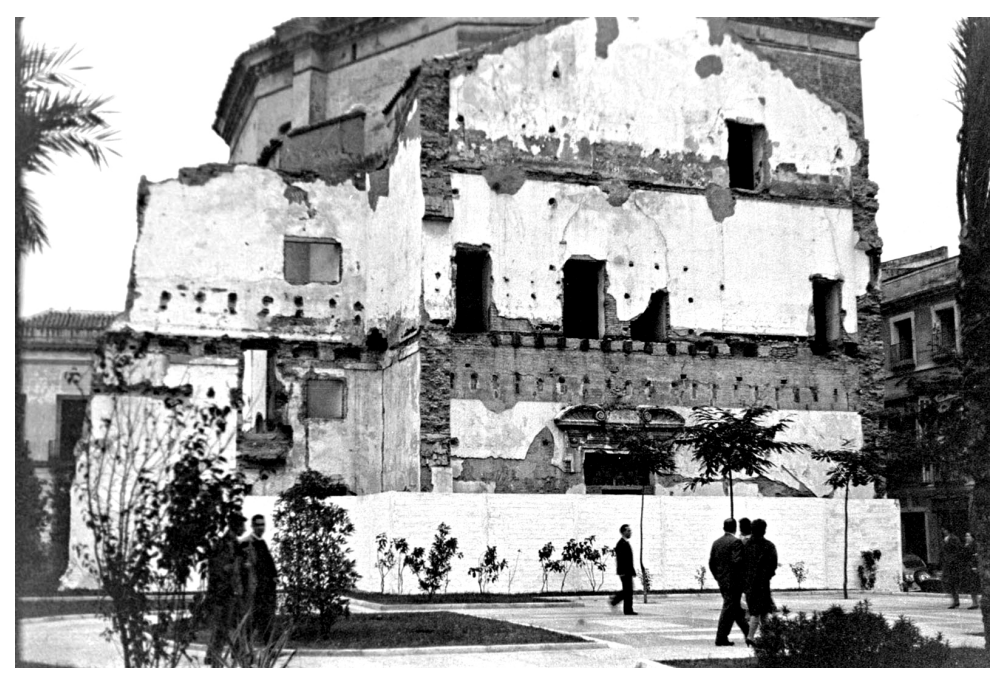


Figura 7. Plano de planta baja, cubierta en estado actual y de la zona de cubierta reformada de la iglesia perteneciente al proyecto de Félix Hernández de 1962. Fuente: MECD, AGA, (03)115 $26 / 251$.

Figura 8. Plano de sección longitudinal de la iglesia con representación del balcón con sus peldaños de acceso y el esquema de la buhardilla de la fachada sur. Proyecto de Félix Hernández de 1962. Fuente: MECD, AGA, (03)115 26/251.

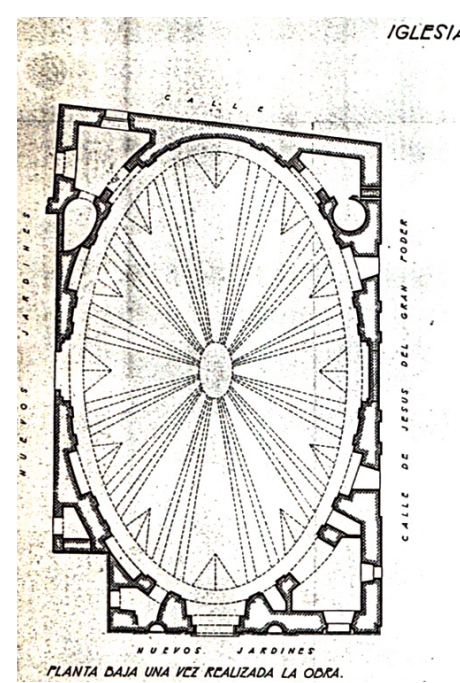

GLESIA DEL COLEGIO DE SAN HERMENEGILDO EN SEVILLA
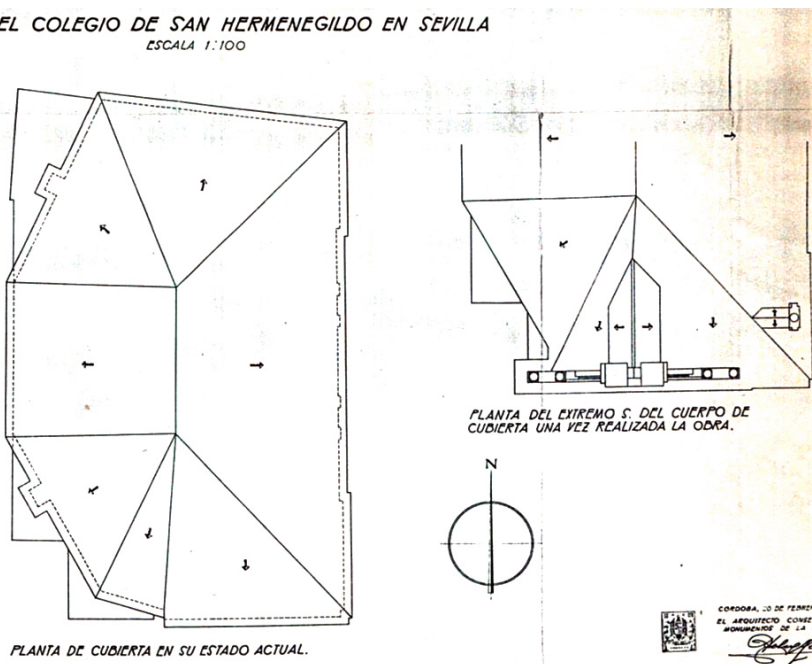

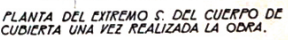
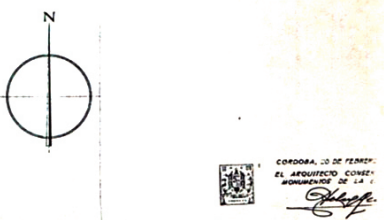

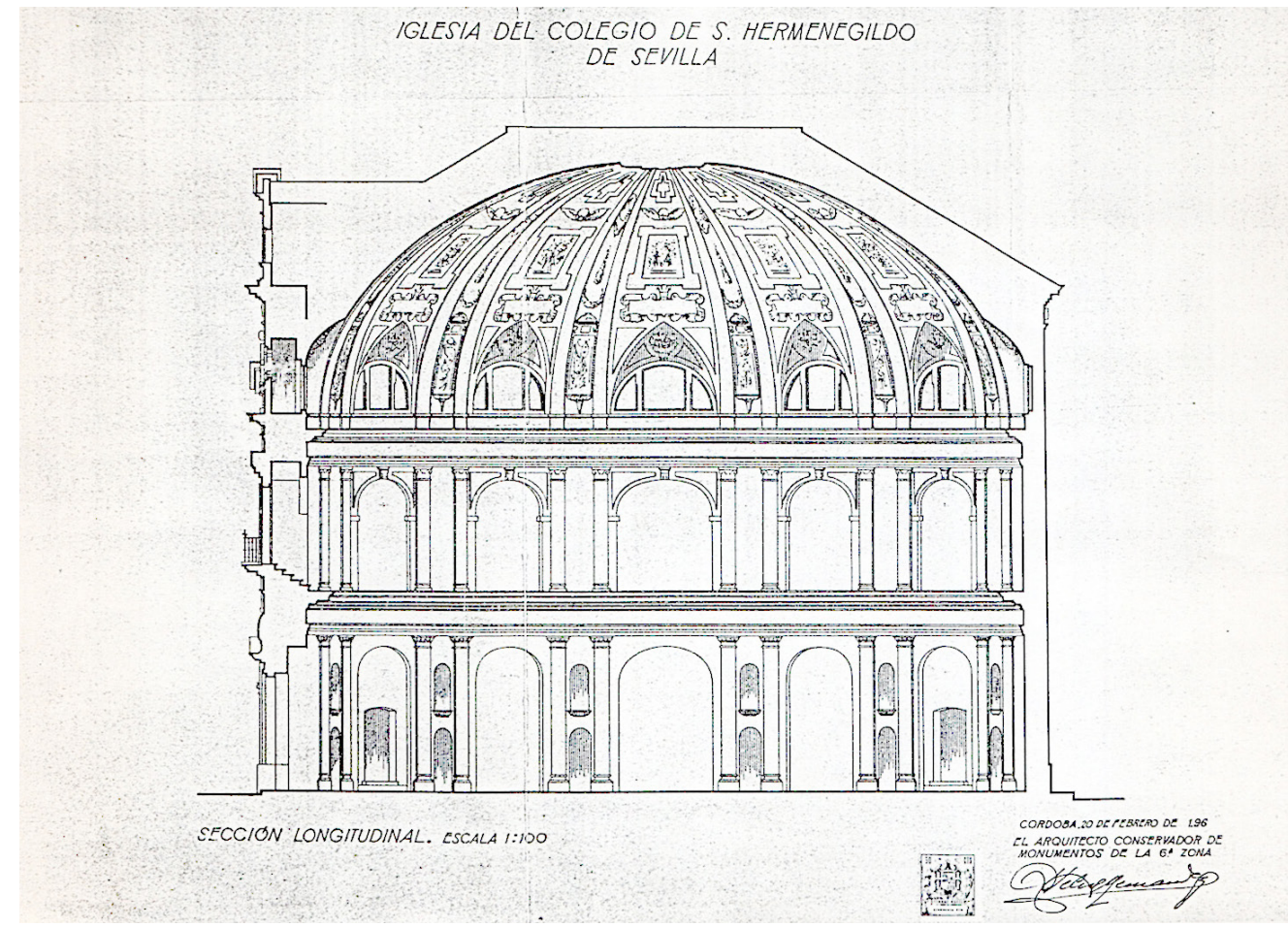

105 y 280).

A partir del tercer proyecto Hernández fue aportando soluciones para restituir una imagen digna al edificio y adecuarlo convenientemente a su nuevo entorno, estableciéndose desde un principio, aunque de forma somera, las terminaciones que pretendía dar $\mathrm{y}$ que, con algunas variaciones, finalmente se realizaron. Así, la memoria del tercer proyecto (Hernández 1962a) apuntaba, entre otras obras, la realización de un ándito voladizo por encima de la cornisa corrida en el espacio principal de la iglesia y la de una escalinata para comunicación con el balcón de la fachada sur del edificio, sin que hubiese ninguna referencia a la citada fachada, y aún menos a su balcón. El proyecto contenía un plano con la planta baja, la cubierta existente y una zona de cubierta reformada (figura 7); y otro con una sección de la iglesia, donde se apreciaba la escalera de acceso al citado balcón (figura 8). Las mediciones contenian algunas partidas referidas al citado ándito, pero ninguna alusiva a la cubierta; y el presupuesto ya era de 700.000 pts.

El balcón planteado tuvo que requerir el diseño, o al menos el bosquejo de la fachada sur, aun-que el proyecto no contuviese un plano de la misma. Esto quedó corroborado al localizar en el archivo del arquitecto, que se custodia en el Museo Arqueológico de Córdoba (MACO 1961), un plano de julio de 1961 con la leyenda "FACHADA A ORGANIZAR EN TESTERO S.", que contiene la portada de la 
misma ya diseñada por el arquitecto. El balcón, además, introducía un elemento un tanto inusual para la fachada principal de un templo y conllevaba realizar una reforma en el interior del monumento que encarecía la intervención. Como plantea González Varas (2016a:163-200), la singularidad de los edificios religiosos limita o condiciona su reutilización, que en muchas ocasiones se decanta hacia usos culturales; y, probablemente, dadas las características espaciales de la iglesia y al no conocer destino de la misma, el arquitecto analizó sus posibilidades de uso tanto para fines religiosos como culturales, como sugiere un plano de planta, de junio de 1960, localizado su archivo (MACO 1960), que analiza su capacidad de butacas.

En el año siguiente y en el quinto proyecto (Hernández 1963) el arquitecto volvió a centrarse en el edificio originario y en la terminación de la fachada sur. Su memoria contiene la única referencia efectuada a los trabajos en la misma, al apuntar:

...la adición de diversos elementos y labores complementarias, en parte de la obra de canteria que se tiene ejecutada, para dejar en condiciones adecuadas el frontis plagado de desmoches con que quedó el edificio, al ser demolido, hace varios años...

Este proyecto contenía 9 planos: repetidos los dos de plantas y sección del proyecto anterior; el alzado de la fachada sur (figura 9), que resolvía a partir de lo existente y quedando la portada descentrada en la misma; y 6 pequeños planos de detalles, de elementos decorativos de la portada, de cornisas y pretiles y del andén tras el pretil proyectado. Las mediciones contenian asimismo partidas de elementos para terminaciones de fachadas, de elementos decorativos de la portada y fachada sur; y su presupuesto fue de 1.627.114,41 pesetas.

La cantidad de detalles decorativos de la fachada sur evidencia el interés de Hernández en darle importancia, al ser la que constituía la entrada originaria a la iglesia (figura 10). Ya anteriormente había planteado cambios en la zona de cubierta y remate de esta fachada, pero fue en su cuarto proyecto, de 1963, cuando presentó la portada y los detalles de la misma, con un diseño que repetía el esquema y estilo renacentista de la fachada este del edificio, con alguna licencia manierista como el relate de coronación.

Resalta el rico enmarque de la puerta del cuerpo bajo que, como se aprecia en una fotografía anterior a la intervención, era el marco original (puede ser una reconstrucción del mismo) de dicha puerta (figura 11), salvo el escudo que lo corona. Así pues, el arquitecto lo conservó integrándolo como eje central en la portada de nuevo diseño, manteniendo así una consigna repetida en sus proyectos:

En su materialidad y en cuanto se supone consolidación o resanado de elementos antiguos, esta obra se realizará con absoluto respeto, asi de los elementos y organizaciones originarias, como de cuanto, constituyendo modificación introducida en la que, en cada caso, cuente como efectiva disposición primiti$v a$, ofrezca en sí reconocido interés, artística o

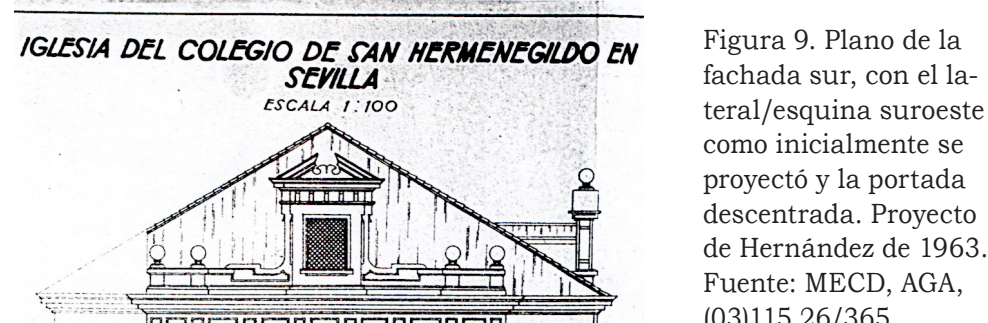
(03)115 26/365.
Figura 10. Dos planos de detalles de la portada y cornisa de la fachada sur. Proyecto de Hernández de 1963. Fuente: MECD, AGA, (03)115 26/365.

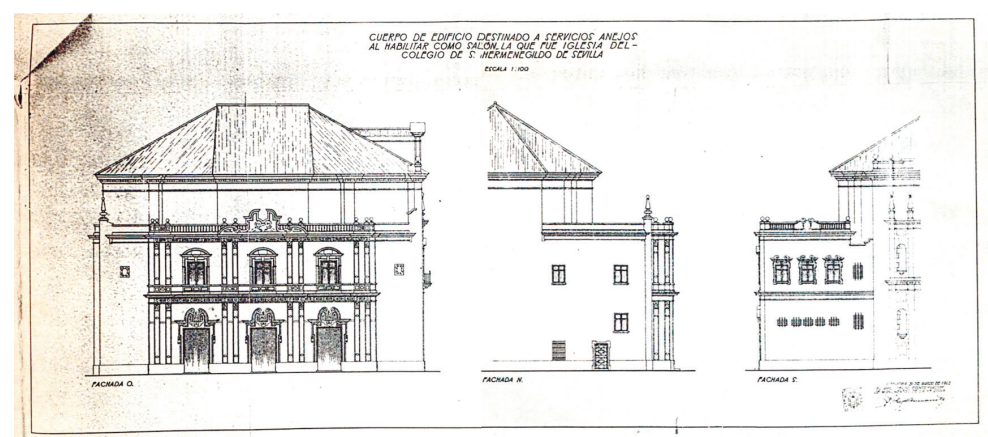


Figura 11. Remate original de la puerta de entrada a la iglesia que quedó tras el derribo, y que Hernández respetó en el diseño de la portada. Fuente: ( ) ICAS-SAHP. Fototeca Municipal de Sevilla. Fondo Cubiles (detalle). Capilla de San Hermenegildo en obras. Exterior. 091960.

Figura 12. Ejecución de la buhardilla, cornisa y elementos de remate de la fachada sur. Fuente: (C) ICAS-SAHP. Fototeca Municipal de Sevilla, fondo Serrano. Capilla de San Hermenegildo en obras. Exterior Remate. 1963.
Figura 13. Plano de plantas y sección del edificio de servicio. Proyecto no ejecutado de Félix Hernández de 1962. Fuente: MECD, AGA, (03)115 26/377. Se destaca la situación de la escalera en la esquina noroeste y la solución dada a la esquina suroeste.

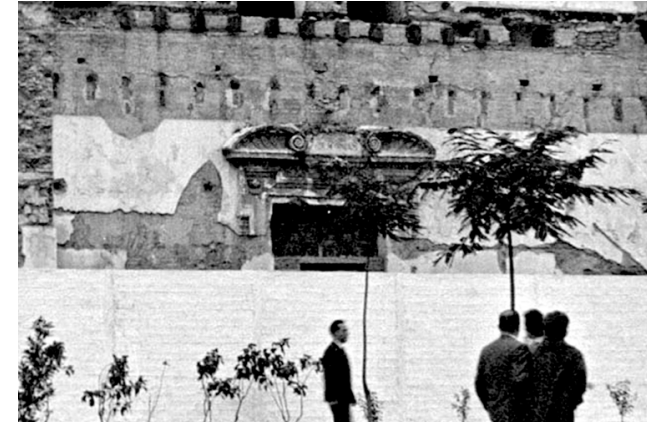

gún diseñó Hernández, dejaba a ésta descentrada en lo que constituía la fachada sur resultante de la iglesia tras el derribo; y no será hasta 1965, en un proyecto posterior, cuando el arquitecto auxiliar, Rafael Manzano Martos, se plantee este problema y resuelva la composición y simetría de dicha fachada.

Una fotografía de 1963 muestra cómo las obras de remate de la portada y de las cubiertas, incluida la buhardilla sur, estaban muy avanzadas (figura 12). Fue una actuación que puede considerarse como un ejemplo más de la corriente denominada conservadora de la posguerra española, seguidora o afin a la teoría de la restauración en estilo (tan denostada posteriormente), al encajar totalmente con la frase muchas veces repetida de Viollet le Duc, "Restaurar un edificio no es conservarlo, repararlo o rehacerlo, es repristinarlo a un estado de completación que puede no haber tenido en ningún tiempo".

La resolución final del monumento y de la fachada sur, con la composición de su portada, tal y como se terminó tuvo aún que esperar algunos años y proyectos. Así, los proyectos cuarto (Hernández 1962b) y sexto (Manzano 1965) trataron de la realización de "obras de organización en cuerpo de edificio destinado a servicios accesorios y que constituya fachada por su frente oeste"; ya que el edificio de la iglesia había quedado reducido al cuerpo de la misma tras la demolición del cuartel, y su posible reutilización requería un mínimo de espacios para dependencias de servicio. Además, también era necesario y

Ahora bien, como ya se ha señalado, el respetar y centrar el hueco en la portada se-

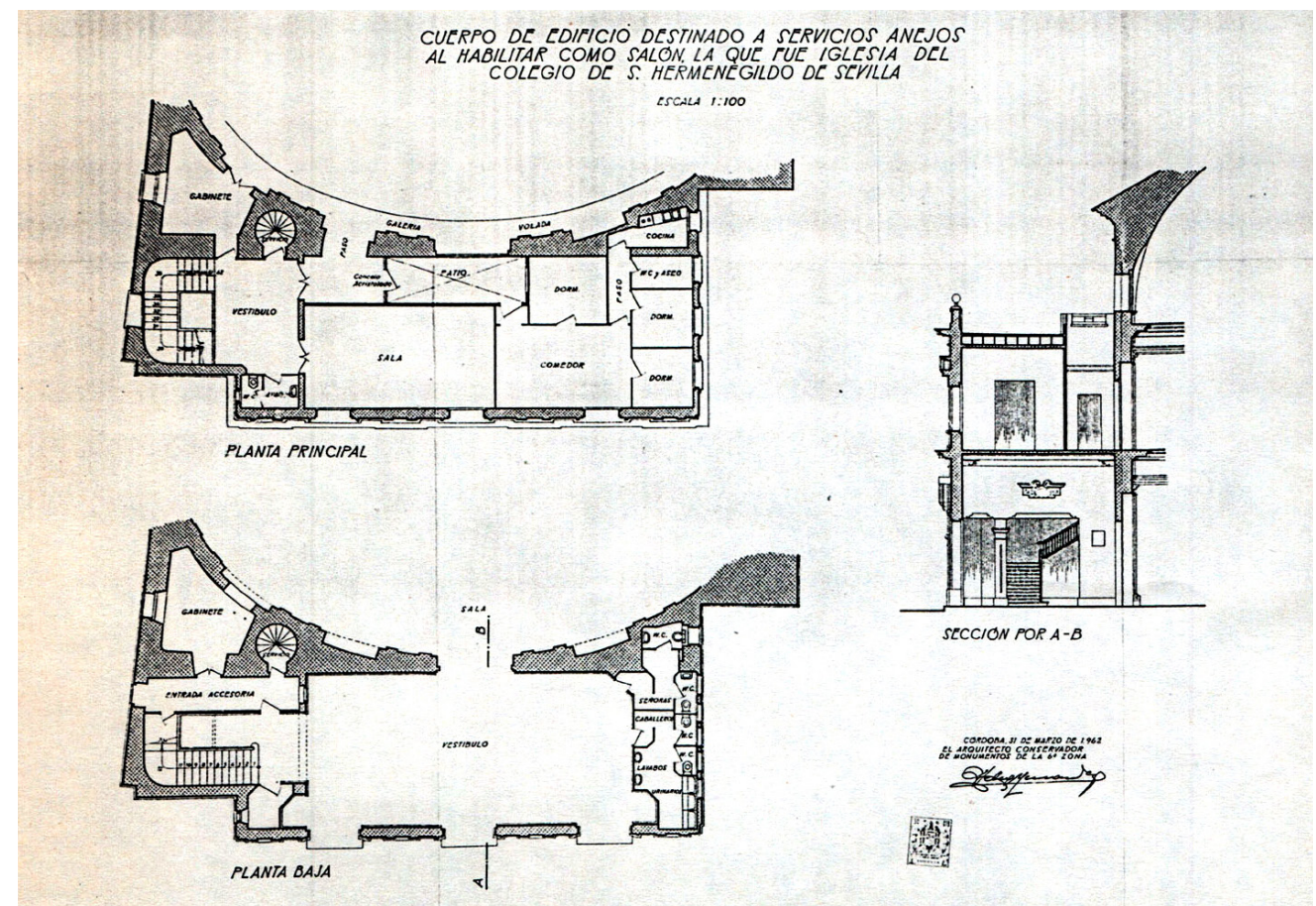




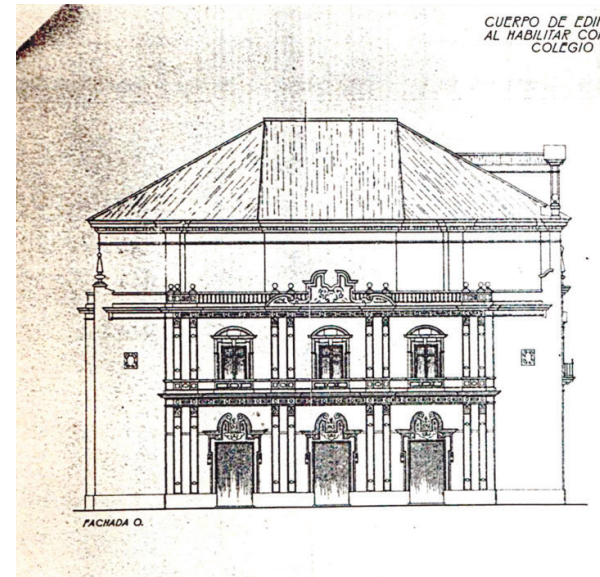

urgente dotar al edificio de una fachada hacia la plaza recién generada. Hernández planteó una construcción de nueva planta, definida por la planimetría y con un presupuesto de 1.779.150,24 pts. Diseñó un edificio de menor altura y anchura que el cuerpo de la iglesia, que quedaba claramente diferenciado (figura 13).

Sus fachadas eran manieristas; quizás en un intento por parte del arquitecto de focalizar y potenciar esta entrada del edificio, de relacionarla con rica ornamentación la sala abovedada de la iglesia o con otras obras del arquitecto Pedro Sánchez, o de adaptarla en lo posible al gusto más barroco asociado a los edificios religiosos sevillanos (figura 14). Fue un proyecto un tanto "arriesgado" pues el edificio no tenía aún un uso definido (AMS 1959) y no fue el que finalmente se ejecutó. ${ }^{7}$

El posterior proyecto del arquitecto auxiliar Rafael Manzano para el edificio de servicios contó con un presupuesto de $1.382 .539,84$ pts. y fue el que finalmente se ejecutó. El arquitecto, conociendo ya el uso asignado al edificio, mantuvo su volumen principal, aunque lo redistribuyó y rediseñó las fachadas, a las que les dio formas renacentistas muy puras y de gran belleza, y para las que se inspiró en el dibujo y la maqueta de Miguel Ángel para la fachada de San Lorenzo de Florencia (figura 15). ${ }^{8}$

En lo que se refiere al problema de la autenticidad de los monumentos, la solución dada por los arquitectos para esta construcción de nueva planta añadida y su diseño es cercana a las ideas planteadas por Boito y a los principios del "restauro scientifico", recogidos en el documento redactado desde el IV Congreso nacional de Ingenieros y Arquitectos de Roma de 1883; en el que en lo referente a los añadidos, se aceptaba "que se completasen partes desaparecidas o que nunca hubieran existido, pero distinguiendo lo añadido,
Figura 14. Plano de alzados del edificio de servicio. Proyecto no ejecutado de Félix Hernández de 1962. Fuente: MECD, AGA, (03)115 26/377. aunque sin perturbar la apariencia original". De esta forma, como apuntan Hernández León (2013:81-83) y Otero-Pailos (2016:2528), se acepta que la nueva unidad creada es la que describe su historia concreta, la que integra sus modificaciones y añadidos a lo largo del tiempo, conformando su biografia.

Y Manzano fue también quien planteó, en el proyecto de 1965, una terminación para la esquina suroeste del edificio originario que resolvía el centrar la portada de la fachada sur de la iglesia (figura 16); lo que conllevaba la modificación de la cubierta de esta zona; y fue la solución definitiva
Figura 15. Plano de alzado principal y planta baja del edificio de servicio. Proyecto de Rafael Manzano de 1965. Redistribución del edificio, con cambio de situación de la escalera y el consiguiente volumen resultante. Fuente: MECD, AGA, (03)115 26/215.

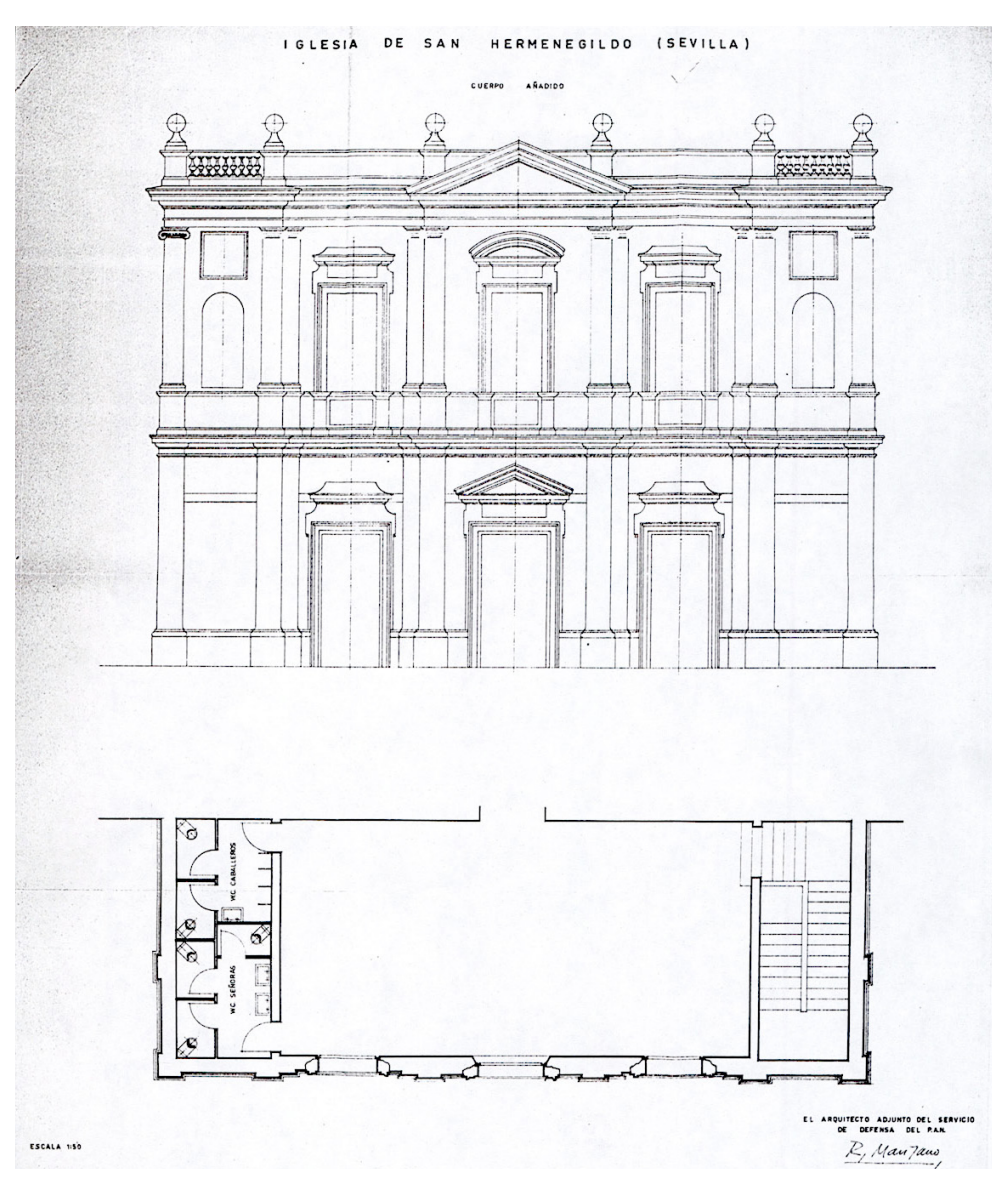


Figura 16. Plano de planta primera del edificio de servicio. Proyecto de Rafael Manzano de 1965. Recoge la terminación de la esquina sur oeste para el cuerpo originario de la iglesia, logrando con ello dar simetría a la fachada sur. Fuente: MECD, AGA, (03)115 26/215.

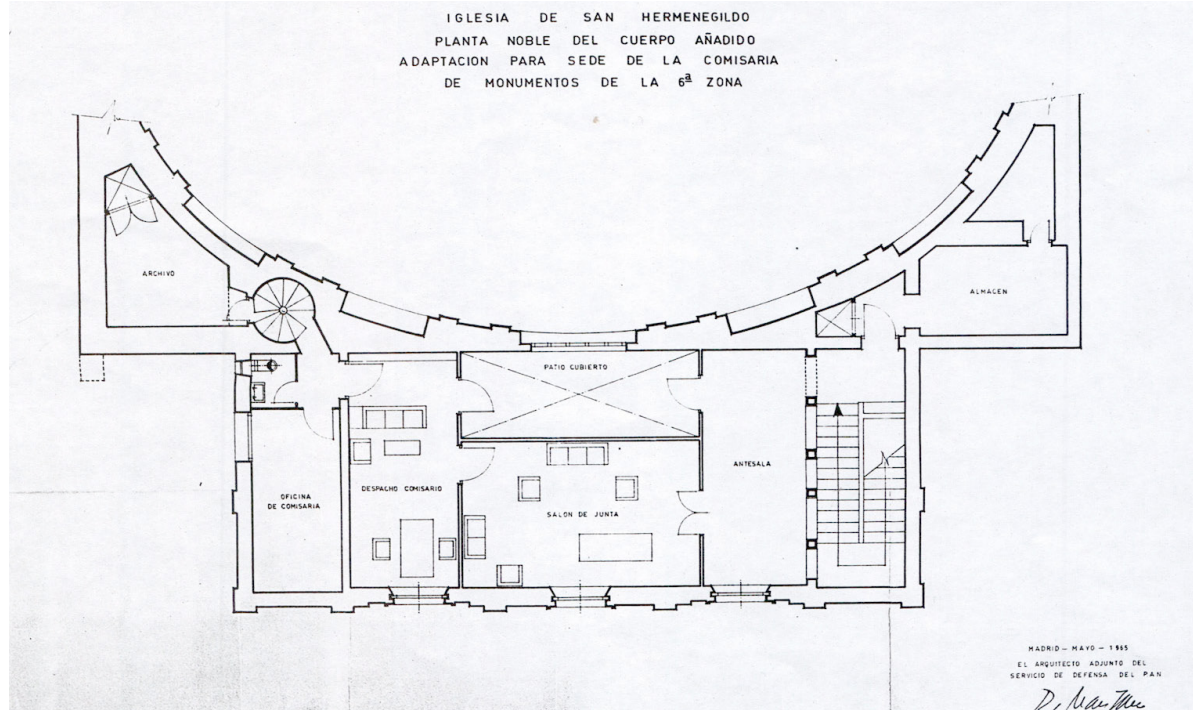

dada (figura 1). Así, su memoria, entre otras cuestiones, indicaba que el exterior del edificio era un sencillo cuadrilátero circunscrito a la elipse,

...al que le falta el ángulo N.O. [es un error de orientación, pues se trata del suroeste], que quedaba embebido en el convento. El edificio, por la misma razón, carecía de fachada norte, donde estuvo el cuerpo claustral... En anualidades anteriores se edificó alli un cuerpo adosado con el fin de darle fachada por ese frente, al par de crear un gran vestíbulo y los servicios necesarios para el nuevo uso a que va a estar destinado el edificio: gran sala de conciertos para lo que reúne excelentes condiciones.

La construcción de esta fachada, y la que decora los pies de la iglesia parece exigir la construcción desde sus cimientos del cuerpo del ángulo N.O. del edificio [es el suroeste], pues de lo contrario quedaría rota para siempre la euritmia y la simetría del edificio en su fachada principal.
Los tres últimos proyectos, (Hernández 1965 y 1966, Hernández y Manzano 1967), ultimaron las obras exteriores de la iglesia, si bien fundamentalmente dos de ellos, con unos respectivos presupuestos de 1.168.707,96 y $1.286 .754,13$ pts., se centraron en la recuperación y embellecimiento del interior del salón (tema de otro trabajo); y el último, con un presupuesto de 2.027.412,14 pts., planteó las obras de terminación de la restauración de la globalidad del edificio ${ }^{9}$. En las partidas de mediciones de los primeros se localizan unas referentes a cierres al exterior de hierro, a "remates de piedra de elaboración artificial en los extremos del cumbrero de la cubierta" y a un escudo sobre la puerta de la fachada sur, que remataba la fachada; y el último incluyó la generación de un patio en la esquina noroeste y la organización de jardinería en el mismo (figura 17) y aportó un plano de la fachada sur con la construcción de la esquina suroeste y la portada centrada tal y como hoy
Figura 17. Fachada oeste a Plaza de la Concordia. Cuerpo de servicios añadido y patio generado en la esquina noroeste. Fotografia: $\mathrm{M}^{\mathrm{a}}$ Gracia Gómez de Terreros G.

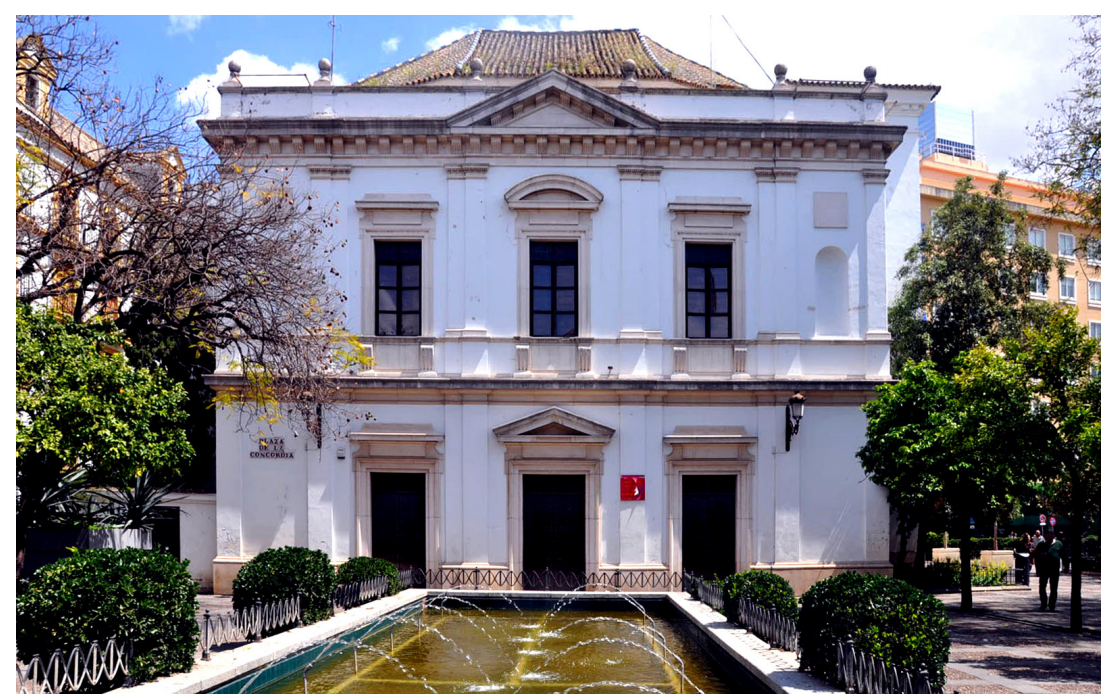


se muestra (figura 1). El presupuesto total invertido por la Dirección General de BBAA fue de 10.331.678,72 ptas., muy alejado del presupuesto del Ayuntamiento (supuso un aumento del $516,36 \%$ ). La intervención realizada fue mucho más extensa y completa que lo inicialmente planteado, y dejó al monumento listo para su uso y con una imagen digna y adecuada al nuevo entorno donde se ubicaba; pero con la posibilidad, más bien el peligro, de constituirse como un falso histórico. El edificio restaurado se estrenó a finales de 1967 (Quintaval 1967).

\section{Epilogo}

La drástica intervención urbanística del derribo del cuartel no tuvo debate previo y no fue una medida acertada desde el punto de vista de la conservación patrimonial, al producir un cambio radical, más bien descomposición, de un edificio monumental que exigió una drástica intervención para la devolución de su dignidad perdida y su adecuación al nuevo entorno, con el riesgo de pérdida de autenticidad. No es de extrañar que la Declaración de Ámsterdam, en 1975, estableciera:

...la planificación urbana y la ordenación del territorio deben integrar las exigencias de la conservación del patrimonio arquitectónico y no tratarla de forma fraccionaria o como un elemento secundario, como ha sucedido a menudo en el pasado reciente. A partir de ahora, es indispensable un diálogo permanente entre los conservadores y los urbanistas.

En lo que respecta a la iglesia, afirmando lo que Fernández-Galiano (2017:3) considera, la intervención arquitectónica sobre antiguos vestigios es una manera de dotarlos de una segunda vida. Goya aseguraba que "el tiempo pinta", y es evidente que su transcurso "también construye", dando al patrimonio una voz irreemplazable cuya desaparición empobrecería la construcción coral del entorno humano. Es evidente que la intervención y transformación de la iglesia fue necesaria, y la restitución de la imagen "adecuada y digna” efectuada se ajustó a la época y lugar en que se realizó y a los arquitectos que intervinieron para ello. Hernández León (2013:9) afirma que,

Restaurar es una intencionada lucha contra el deterioro del monumento, a veces para evitar un riesgo cierto de destrucción, otras para recuperarlo de un estado de postración... ...pero todas estas estrategias tienen en común (y siempre como consecuencia) la trans- formación del objeto en cuanto afectan a su especifica historicidad.

Las actuaciones en el monumento muestran dos procederes diferentes. El cuerpo de servicio adosado al de la iglesia es perfectamente distinguible del edificio original, por sus dimensiones y volumen y, si bien mantiene el estilo arquitectónico, no genera conflictos en su autenticidad. Por el contrario, la nueva fachada sur, como se ha demostrado, ha generado un falso en el edificio, si atendemos a la definición de autenticidad de Paul Philippot que recoge Jokilehto (2009: 80), "the authenticity of a work of art is the internal unity of the mental process and of the material realization of the work". El punto 9 del Documento de Nara sobre Autenticidad (ICOMOS 1994) ciertamente avanza al declarar:

La conservación del patrimonio cultural en todas sus formas y periodos históricos, parte de los valores atribuidos a éste. Nuestra habilidad para entender estos valores depende, en parte, del grado en el cual puedan entenderse las fuentes de información sobre estos valores, como creíbles o veraces. El conocimiento y comprensión de estas fuentes de información, en relación con las características originales y derivadas del patrimonio cultural, y su significado, son requisito básico para evaluar todos los aspectos de la autenticidad.

De esta forma, lo que es falso surge cuando las fuentes de información son alteradas o falsificadas, bien de forma intencionada, o no, adaptadas a modas o justificadas con fines turísticos o funcionales, como ha sido el caso de la portada de San Hermenegildo.

Pero, por otra parte, debemos ponderar el monumento como un documento histórico en sí mismo, como indica González-Varas (2015: 123-125), un "unicum", un objeto singular, único e irrepetible. El bien es creado en una época histórica, con un motivo y materiales trabajados de una determinada manera, pero su singularidad la proporcionan especialmente los acontecimientos que ha sufrido a lo largo del tiempo; es decir, esa historia concreta y única, de la que son testimonio los signos que el tiempo o la mano del hombre han ido dejando sobre su materialidad o sobre sus significados rememorativos acumulados. Por ello debe quedar ligada toda intervención restauradora, con su contextualización e historia. El monumento como documento histórico es un objeto único e irrepetible, con una singularidad que es aportada por los aconte- 
cimientos que ha sufrido en el tiempo. En su materialidad es donde quedan reflejados sus aconteceres concretos y único, que constituyen el testimonio que el tiempo o la mano del hombre han ido dejando en él. Despejar un bien de su historia es una forma de devaluarlo, de generar un incompleto, o lo que es peor, generar una falsa imagen.

El trabajo realizado constata la importancia de la documentación patrimonial aún existente, y la rápida pérdida de la memoria histórica del hombre en lo que a patrimonio monumental se refiere, siendo para ambos aspectos la iglesia de San Hermenegildo un ejemplo axiomático.

\section{Notas}

1 El presente trabajo se publica en el marco de los proyectos de investigación I+D del Programa Estatal de Fomento de la Investigación Científica y Técnica de Excelencia Ruinas, expolios e intervenciones en el patrimonio cultural, ref. DER2014-52947-P, financiado por el Ministerio de Economia y Competitividad; y Los arquitectos restauradores de la España del franquismo. De la continuidad de la ley de 1933 a la recepción de la teoría europea, ref. HAR2015-68109-P, financiado por el Ministerio de Economía y Competitividad y los fondos FEDER.

2 El 18 de julio de 1961 el Ayuntamiento colocó en la fachada de la iglesia una lápida conmemorativa "Al cumplirse el XXV aniversario de tan excelsa jornada”. La lápida se retiró años después, dejándose rota y arrinconada en el jardín del convento de Santa Clara.

3 Noticia de $\mathrm{ABC}$, firmada por el Presidente de la Real Academia de Bellas Artes y de la Comisión de Monumentos. La iglesia se declaró Monumento por el Decreto 845/1959, de 13 de mayo de 1959, BOE de 1 de junio de 1959.

4 El proyecto de reforma interior de junio de 1958 eliminaba los aparcamientos y otro de septiembre del mismo año proyectaba la pavimentación y jardinería del solar. Los expedientes del AMS contienen planos de proyectos, de trazados de calles y zonificaciones, sobre expropiaciones, minutas de honorarios, etc.

5 Félix Hernández Giménez (1889-1975) fue arquitecto jefe de la $6^{\mathrm{a}}$ Zona (incluía Andalucía occidental, Badajoz y Canarias) tras la Guerra Civil y hasta 1975. Sus intervenciones más destacadas las realizó en el Patio de los Naranjos de la Catedral de Sevilla, Ruinas de Itálica, Teatro de Mérida, Mezquita de Córdoba y Madinat al-Zahra y todas ellas se han analizado en diversas publicaciones. Sus actuaciones, análisis arqueológicos e investigaciones, le convirtieron en un experto en arquitectura hispanomusulmana.

6 En general, no fue la $6^{a}$ una zona de grandes destrucciones debidas a la contienda civil; reduciéndose los daños a los primeros dias y semanas, cuando numerosos templos fueron incendiados o saqueados (Gómez de Terreros 2010:19)

7 En octubre 1962, 6 meses después del citado proyecto, la Dirección General BBAA informó al Alcalde que las obras iban muy avanzadas e interesaba conocer el destino dado al monumento para terminación de las obras. En la sesión del Ayuntamiento celebrada a final de dicho mes se decidió su habilitación como Salón de Actos para Congresos, Reuniones, Conferencias, Conciertos, etc. de carácter oficial.

8 En una entrevista personal de 3 de marzo de 2017, el arquitecto aportó este interesante dato.

9 La documentación analizada referente a los dos últimos proyectos es la contenida en el archivo del arquitecto. Son borradores de los mismos con correcciones a mano, pero que se corresponden con los existentes en el AGA fechados en 1967 (año en que debieron ser aprobados. Corrobora esto el que el presupuesto general del penúltimo coincida con la subvención otorgada por la Dirección General de BBAA en 1967; y que coincida la autoría de ambos proyectos.

\section{Bibliografia}

ABC. Edición de Andalucía. 1957. "Sevilla al dia". 16.847: 21

ABC. Edición de Andalucía. 1961a. "Brillante recepción en Capitanía General presidida por el señor González Gallarza. Ofrenda de flores en la tumba de Queipo de Llano y descubrimiento de una lápida en el antiguo cuartel de San Hermenegildo". 18.060:18.

ABC. Edición Andalucía. 1961b. "Sevilla al día". 18.155: 29

ACMHAPS. 1957. Acta de sesión ordinaria de la Comisión de Monumentos, 20 de septiembre de 1957. Libro de Actas 5: 333.

AMS. 1959-1961. San Hermenegildo. Ordenación Urbana. Proyectos y Ejecuciones. Exps. 31/1959, 36/1959, 45/1959, 47/1959, 48/1959 y 49/1959.

AMS.1959. San Hermenegildo. Ordenación Urbana. Proyectos y Ejecuciones. Exp. 38/1959.

Ayús y Rubio, Manuel. 2017. Réquiem por el patrimonio edilicio de la ciudad. La Administración: Principal artífice de la Destrucción de las Arquitecturas y del Paisaje de la Ciudad. Madrid: Derecho y Naturaleza.

Criado Mainar, Jesús. 2010. Contribución de la Compañía de Jesús al campo de la Arquitectura y de las Artes plásticas. En: Betrán, José Luis (ed.) La Compañia de Jesús y su proyección mediática en el mundo hispánico durante la Edad Moderna. Madrid: Sílex. 264-265.

CRUZ IsIDORO, Fernando. 2001. Alonso de Vandelvira (1544-ca.1626/7) Tratadista y arquitecto anda luz. Sevilla: Secretariado publicaciones Universidad de Sevilla.

Fernández-Galiano, Luis. 2017. Cirugía menor. Arquitectura Viva, 194:3.

FERnÁndez Salinas, Víctor. 1998. La reforma interior de Sevilla entre 1940 y 1959. Sevilla: Junta de Andalucía y Universidad de Sevilla.

Gómez de Terreros Guardiola, Ma del Valle y Gómez de Terreros Guardiola, Ma Gracia. 2009. La Capilla Sevillana de Santa María de Jesús. Obras y Restauraciones, 1909-2006. En: Actas del XI Simposio Internacional de Mudejarismo. Teruel: Centro de estudios Mudéjares. 87-106.

Gómez de Terreros Guardiola, Ma del Valle y Gómez de Terreros Guardiola, $M^{a}$ Gracia. 2010. Sevilla en zona nacional: destruccio- 
nes, restauraciones y criterios de intervención. En: García Cuetos, $\mathrm{M}^{\mathrm{a}}$ Pilar, Almarcha Núñez-Herrador, $\mathrm{M}^{\mathrm{a}}$ Esther y Hernández Martínez, Ascensión (coords.) Restaurando la memoria. España e Italia ante la recuperación monumental de posguerra. Gijón: Ediciones Trea. 17-39.

Gómez Estern, Luis. 1959. Proyecto de consolidación y restauración de la capilla del Cuartel de San Hermenegildo. Presupuesto. Sevilla. Archivo Félix Hernández, Museo Arqueológico de Córdoba (MACO), FH19 [L2 F C8].

GonZÁlez-VAras IBÁÑez, Ignacio. 2015. Patrimonio cultural. Conceptos, debates y problemas. Madrid: Ediciones Cátedra.

GonzÁlez-VARAS IbÁÑez, Ignacio. 2016a. Ciudad, Paisaje y territorio. Concepto, métodos y experiencias. Madrid: Munilla-Lería.

GonZÁleZ-VARAs IBÁÑEZ, Ignacio. 2016b. Los espacios de la memoria (y del olvido) en la ciudad y sus discursos narrativos: creación, transformación, revitalización y tematización. En: Calatrava Escobar, Juan, García Pérez, Francisco y Arredondo Garrido, David (eds.) La cultura y la ciudad. Granada: Universidad de Granada y Campus Universitario de Cartuja. 561-568.

Hernández Díaz, José. 1958. "La Iglesia de San Hermenegildo". ABC. Edición de Andalucia. 17.102: 23-24.

Hernández Giménez, Félix.1960.Proyecto de obras de reparación a llevar a cabo en la iglesia de San Hermenegildo en Sevilla, 21 de junio. MECD, AGA, (03)115 26/152.

Hernández Giménez, Félix. 1961. Proyecto de obras en la iglesia del Colegio San Hermenegildo de $\mathrm{Se}$ villa, 12 de mayo. MECD, AGA, (03)115 26/361.

Hernández Giménez, Félix. 1962a. Proyecto de obras a efectuar en la iglesia del que fue Colegio de $S$. Hermenegildo de Sevilla, 20 de febrero. MECD, AGA, (03)115 26/251.

Hernández Giménez, Félix. 1962b. Proyecto de obras de organización en cuerpo de edificio destinado a servicios accesorios y que constituya fachada por su frente Oeste, de lo que fue iglesia del Colegio de $S$. Hermenegildo de Sevilla, 31 de marzo. AGA, MECD, (03)115 26/377.

Hernández Giménez, Félix .1963. Proyecto de obras de mera conservación a llevar a cabo en la que fue iglesia del Colegio de S. Hermenegildo de Sevilla. 27 de septiembre, AGA, MECD, (03)115 26/365.

Hernández Giménez, Félix. 1965. Proyecto de obras de conservación a llevar a cabo en la iglesia de S. Hermenegildo de Sevilla. 19 de octubre. AGA, MECD, (03)115 26/215.

Hernández Giménez, Félix. 1966. Borrador de proyecto de obra de mera conservación en la que fue iglesia del Colegio de S. Hermenegildo de Sevilla, 28 de febrero. MACO, FH20 Subcarpeta 13 [L6 F C11].

Hernández Giménez, Félix y Manzano Martos, Rafael (1967) Borrador de Proyecto de obra de mera conservación en la que fue iglesia del Colegio de S. Hermenegildo de Sevilla y en el pabellón de servicios adicionado a la misma, 9 de noviembre. MACO, FH20 Subcarpeta 13 [L6 F C11].

Hernández León, Juan Miguel .2013. Autenticidad y monumento. Del rito de Lázaro al de Pigmalión. Madrid: Abada Editores.

IAPH. Iglesia del antiguo Convento de San Hermenegildo. Bases de datos de patrimonio cultu- ral. Patrimonio inmueble de Andalucia. http:// www.iaph.es/patrimonio-inmueble-andalucia/ resumen.do?id=i19280 (visitado 7 de ene. 2016)

ICOMOS.1994. Documento de Nara sobre autenticidad. Punto 9. Japón.

ISGAS. Antigua Iglesia del Convento de San Hermenegildo. Epigrafe $1^{\circ}$ - Inmuebles, asiento 181.

Joкilento, Juka. 2009. Conservation Principles in the International Context. En: Richmond, Alison y Bracker, Alison (eds.), Conservation. Principles, Dilemmas and Uncomfortable Truths. London: Elservier Ltd and Victoria and Albert Museum. 73-83.

MACO. 1960. FH19 [L2 F C1].

MACO. 1961. FH19 [L5 F C18].

Manzano Martos, Rafael.1965. Proyecto de obras de restauración en la iglesia de San Hermenegildo. Madrid, mayo, AGA, MECD, (03)115 26/215.

Marín Fidalgo, Ana. 2008. Más datos sobre el Colegio de San Hermenegildo de Sevilla. En: Archivo Hispalense, XCI: 303-323.

Morales, Alfredo José et al. 2004. Guía artística de Sevilla y su provincia ( $2^{a}$ ed.). Tomo I, Sevilla: Fundación José Manuel Lara y Diputación de Sevilla.

Muñoz Cosme, Alfonso. 1989. La conservación del Patrimonio Arquitectónico español. Madrid: Ministerio de Cultura.

OTOUAS. 1957. Anteproyecto de reforma interior del solar resultante del derribo del Cuartel y del picadero militar. ACMHAPS. Caja Planos y proyectos de Edificios. Sevilla. 18.

Otero-Pailos, Jorge. 2016. Experimental Preservation: The Potential of Not-Me Creations. En: Otero-Pailos, Jorge, Langdalen, Erik y Arrhenius, Thordis (eds.) Experimental Preservation. Zürich, Switzerland: Lars Müller Publishers and the authors. pp. 25-28.

Pérez SÁnchez, Alfonso E. y Navarrete Prieto, Benito. 1996. Sobre Herrera "El Viejo". Archivo Español de Arte, 69, 276: 365-387.

Quintabal. 1967. ABC. Edición de Andalucía. "Sevilla al dia". 20.017: 47.

Rodríguez G. De Ceballos, Alonso.1970. El arquitecto hermano Pedro Sánchez. Archivo Español de Arte, 43, 169: 51-82.

SAlas, Nicolás. 2008. Sevilla desaparecida. Álbum de la destrucción de la ciudad (Siglos XIX y XX). Sevilla: Guadalturia.

Stanley-Price, Nicholas. 2009. The reconstruction of Ruins: Principles and Practice. En: Richmond, Alison y Bracker, Alison (eds.) Conservation. Principles, Dilemmas and Uncomfortable Truths. London: Elservier Ltd and Victoria and Albert Museum: 32-46.

TEuido Jiménez, Javier. 2016. La demolición a gran escala como técnica de intervención urbana. La apertura de la Avenida de la Constitución de Sevilla (1906-1927)". En: Informes de la Construcción, 68. doi: http://dx.doi.org/10.3989/ ic. 15.045 .

Villar Movellán, Alberto. 1979. Arquitectura del regionalismo en Sevilla (1900-1935. Sevilla: Diputación Provincial.

Fecha final recepción artículos: 16/04/2018

Fecha aceptación: 27/06/2018

Articulo sometido a revisión por dos revisores independientes por el método doble ciego. on agradecimiento al Archivo General de la Administración de Alcalá de Henares, al Museo Arqueológico de Córdoba, a la Hemeroteca y la Fototeca municipal de Sevilla, a la Fototeca de la Universidad Hispalense, a la Real Academia de Bellas Artes de Santa Isabel de Hungría y al investigador Nicolás Salas. 